\title{
Effects of Electrical Current on Microstructure and Interface Properties of Sn-Ag-Cu/Ag Photovoltaic Ribbons
}

\author{
Kuan-Jen Chen ${ }^{1}$, Fei-Yi Hung ${ }^{2, *}$, Truan-Sheng Lui², Li-Hui Chen ${ }^{2}$, \\ Dai-Wen $\mathrm{Qiu}^{2}$ and Ta-Lung Chou ${ }^{3}$ \\ ${ }^{1}$ The Instrument Center, National Cheng Kung University, Tainan 701, Taiwan \\ ${ }^{2}$ Department of Materials Science and Engineering, Institute of Nanotechnology and Microsystems Engineering, \\ Center for Micro/Nano Science and Engineering, National Cheng Kung University, Tainan 701, Taiwan \\ ${ }^{3}$ HUA Eng Wire \& Cable Co., Ltd., Kaohsiung, Taiwan
}

This study presents an electrical current testing that is based on the $\mathrm{Sn}-x \mathrm{Ag}-0.5 \mathrm{Cu}(x=1,3$ mass $\%)$ photovoltaic (PV) ribbon, and investigates the growth mechanism of the intermetallic compounds (IMCs). The microstructure of both alloy solders contains the eutectic region $\left(\beta-\mathrm{Sn}+\mathrm{Cu}_{6} \mathrm{Sn}_{5}+\mathrm{Ag}_{3} \mathrm{Sn}\right)$ and the base phases $(\beta-\mathrm{Sn})$. The eutectic phases in the $\mathrm{Sn}-3 \mathrm{Ag}-0.5 \mathrm{Cu}(\mathrm{SAC} 305)$ alloy presented a continuous distribution, and its amount was higher. After soldering, the $\mathrm{Cu}_{6} \mathrm{Sn}_{5}$ and $\mathrm{Ag}_{3} \mathrm{Sn}$ IMCs were found at the interfaces, and their morphologies were dominated by Ag contents in the $\mathrm{Sn}-\mathrm{Ag}-\mathrm{Cu}$ (SAC) solder. The whole interfacial characteristics of IMCs were affected after biasing for $40 \mathrm{~h}$. The growth behavior of these IMCs was controlled by the bias-induced thermal diffusion mechanism and the evolution of IMC morphology was dominated by the growth dynamics. The IMCs, formed at the interfaces $(\mathrm{SAC} / \mathrm{Cu}, \mathrm{SAC} / \mathrm{Ag}$ ), dominated the series resistance of the PV ribbon. [doi:10.2320/matertrans.M2013110]

(Received March 21, 2013; Accepted April 23, 2013; Published June 7, 2013)

Keywords: tin-xsilver-0.5copper, photovoltaic ribbon, intermetallic compounds, biasing

\section{Introduction}

The role of photovoltaic (PV) ribbon in the solar cells was soldered onto $\mathrm{Si}$ substrate to collect the photo-generated current. ${ }^{1)}$ Currently, the most solders on the commercial PV ribbons were $\mathrm{Sn}-37 \mathrm{~Pb}$ and $\mathrm{Sn}-36 \mathrm{~Pb}-2 \mathrm{Ag}$ alloys. ${ }^{2,3)}$ These solder materials were $\mathrm{Sn}-\mathrm{Pb}$ alloys that were not environmental and human healthy friendly. Therefore, replacing the $\mathrm{Sn}-\mathrm{Pb}$ solder to lead-free solder was common goal for the electronic packing and the solder industries. Considering the melting point, wettability, mechanical properties, cost and conductivity of the lead-free solder materials, the Sn-based solder alloys ( $\mathrm{Sn}-\mathrm{Ag}, \mathrm{Sn}-\mathrm{Zn}, \mathrm{Sn}-\mathrm{Cu}, \mathrm{Sn}-\mathrm{Ag}-\mathrm{Cu}$ ) have been developed. ${ }^{4-7)}$ Throughout Sn-based alloys, the green $\mathrm{Sn}-$ $\mathrm{Ag}-\mathrm{Cu}$ (SAC) alloys with good wettability and mechanical properties of advantages can be applied in solar substrate. ${ }^{8-10)}$

In recent years, the costs of high Ag content materials were raised due to the prices of the precious metals increased. Amagai et al. indicated that the SAC alloys containing 1.0 1.5 mass \%. Ag have best performance in winding and thermal cycling test. ${ }^{11)}$ Many scholars also used the lower Ag content SAC alloys to study the effects of the tensile stress, shearing stress and thermal fatigue properties on the flip-chip packaging. ${ }^{10,12)}$ However, the literature has never reported the behavior of SAC alloys in PV ribbon. In addition, $\mathrm{Cu}_{6} \mathrm{Sn}_{5}$ and the $\mathrm{Cu}_{3} \mathrm{Sn}$ intermetallic compounds (IMCs) were formed in the SAC solder/Cu interface, ${ }^{13)}$ and the $\mathrm{Ag}_{3} \mathrm{Sn}$ IMC was formed in the SAC solder/Ag interface. ${ }^{14)}$ These IMCs have a high resistance and hardness that caused an increasing internal resistance and the brittleness destruction in the interface. ${ }^{15,16)}$

In this study, the different $\mathrm{Ag}$ contents in the $\mathrm{Sn}-x \mathrm{Ag}$ $0.5 \mathrm{Cu}(x=1,3 \operatorname{mass} \%)$ alloys were used to estimate the

*Corresponding author, E-mail: fyhung@mail.ncku.edu.tw feasibility of PV ribbon application. The growth mechanisms of IMCs in the PV ribbon interfaces ( $\mathrm{SAC} / \mathrm{Cu}, \mathrm{SAC} / \mathrm{Ag}$ ) were investigated. In addition, in the static (soldering) and dynamic (biasing) thermal effects, this study analyzed the interfaces characteristics and the resistance of overall structure to clarify the contribution of IMCs in the PV ribbon.

\section{Experimental Procedures}

The $\mathrm{Sn}-x \mathrm{Ag}-0.5 \mathrm{Cu}(x=1,3$ mass $\%)$ alloy solders were used in PV ribbon. According to $\mathrm{Ag}$ contents in solders, $\mathrm{Sn}-1 \mathrm{mass} \% \mathrm{Ag}-0.5 \mathrm{mass} \% \mathrm{Cu}$ and $\mathrm{Sn}-3 \mathrm{mass} \% \mathrm{Ag}-0.5$ mass $\% \mathrm{Cu}$ alloys were designed as the SAC105 and SAC305, respectively. Fusion current testing (Fig. 1(a)) for SAC alloys was performed using a DC power supply (Gwinstek GPR-1850HD). The alloy specimens were biased with the constant current $(1 \mathrm{~A} / \mathrm{s})$ at room temperature until the fused behavior occurred. The critical fusion current density (CFCD) of solders was calculated according to the fusion current value divided by the cross-section area $\left(5 \times 0.8 \mathrm{~mm}^{2}\right)$.

A pure $\mathrm{Cu}$ ribbon $($ length $=30 \mathrm{~mm}$, width $=2.0 \mathrm{~mm}$, thickness $=0.15 \mathrm{~mm}$ ) was immersed in the molten solder $\left(270^{\circ} \mathrm{C}\right)$ for $1 \mathrm{~s}$ to form the PV ribbon. In order to estimate the feasibility of the SAC105 and SAC305 solders in the $\mathrm{PV}$ ribbon application, these ribbons were soldered to $\mathrm{Ag}$ electrode on $\mathrm{Si}$ substrate. In addition, a DC power supply provided a high current $\left(\sim 50 \mathrm{~A} \cdot \mathrm{cm}^{-2}\right)$ onto PV ribbons in a duration time of $40 \mathrm{~h}$ to investigate the interfacial diffusion behavior. Figure 1(b) shows a schematic illustration of the electrical current testing in the PV ribbons, ${ }^{17)}$ and the dashed line is presented the flowing path of the electrons. Microstructures of solders were examined using the optical microscope (HITACHI, TM-1000). Interfacial characteristics were examined using an ultra-high resolution analytical 

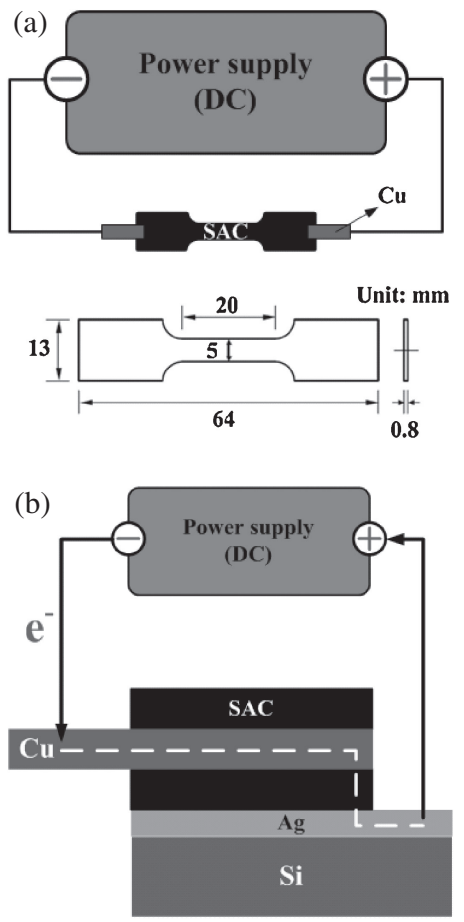

Fig. 1 (a) Schematic diagram of fusion current measurement for SAC alloys. (b) Schematic diagram of electrical current testing in PV ribbon.

electron microscope (JEOL, JEM-2100F CS STEM) and energy-dispersive X-ray (EDX). The series resistances $(\mathrm{Cu} / \mathrm{SAC} / \mathrm{Ag})$ of $\mathrm{PV}$ ribbons were estimated according to the Ohm's law $(\mathrm{V}=\mathrm{IR})$.

\section{Results and Discussion}

Figure 2 shows microstructure metallograph of the SAC105 and SAC305 alloys. The portions of the dark color were eutectic region $\left(\beta-\mathrm{Sn}+\mathrm{Cu}_{6} \mathrm{Sn}_{5}+\mathrm{Ag}_{3} \mathrm{Sn}\right)$; and those of the light color were base phases $(\beta$-Sn). In the case of the SAC105 alloy (Fig. 2(a)), $\beta$-Sn phases presented a continuous distribution, but the $\beta$-Sn phase of the SAC305 alloy displayed a dendrite characteristic (Fig. 2(b)). Comparing the SAC105 with SAC305, the eutectic area of the SAC305 alloy was greater than that of the SAC105 alloy. This result indicated that the amount of IMCs in the SAC305 alloy was higher. The fusion current density of the SAC105 and SAC305 alloys was $1035.6 \mathrm{~A} \cdot \mathrm{cm}^{-2}$ and $986.1 \mathrm{~A} \cdot \mathrm{cm}^{-2}$, respectively (Fig. 3). These fusion current densities were dominated by the internal resistance of the alloys. A greater the internal resistance of the alloy resulted in raising the biasinduced Joule's heat, indicating that this alloy was easier to be fused. In the case of the eutectic region $\left(\beta-\mathrm{Sn}+\mathrm{Cu}_{6} \mathrm{~S}\right.$ $\left.\mathrm{n}_{5}+\mathrm{Ag}_{3} \mathrm{Sn}\right)$, the $\mathrm{Cu}_{6} \mathrm{Sn}_{5}$ was high resistance phase compared to the $\beta$-Sn phase. The eutectic area (high resistance phase) of SAC305 alloy was greater and discontinuous. These results caused the transmission of the electron had a high probability to encounter the high resistance phase. That was why the fusion current density of the SAC305 alloy was lower in the same current testing.

Pure $\mathrm{Cu}$ ribbon was immersed in molten solders (SAC105, $\mathrm{SAC} 305)$ at $275^{\circ} \mathrm{C}$ for $1 \mathrm{~s}$ to obtain PV ribbon. The cross- (a)

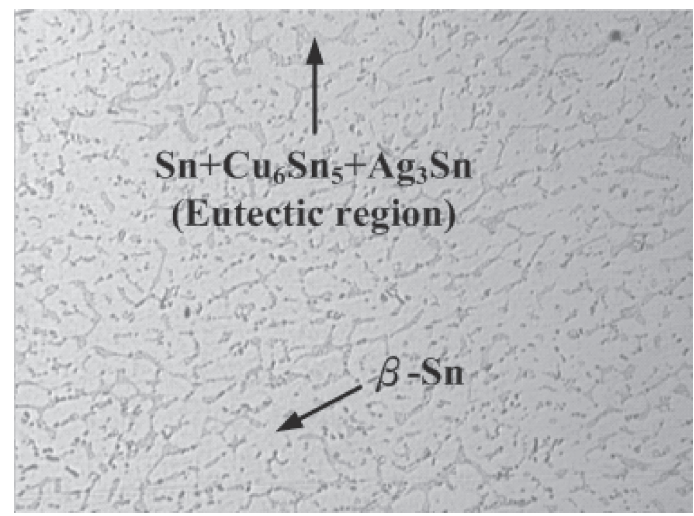

(b)

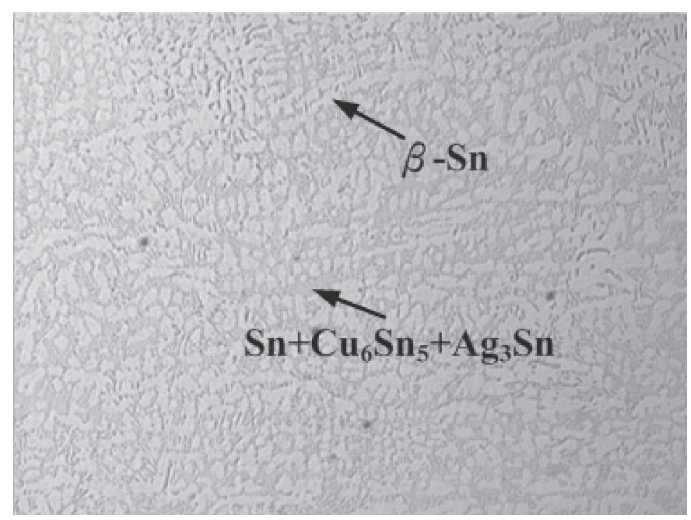

Fig. 2 Microstructure metallograph of (a) SAC105 and (b) SAC305 alloys.

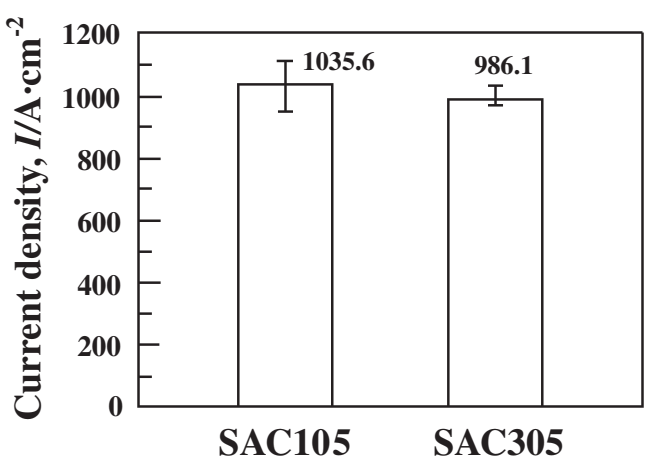

Fig. 3 Fusion current densities of SAC105 and SAC305 alloys.

section images of PV ribbons were carried out, as shown in Fig. 4. It clearly shows that IMC layer was generated at the interfaces between solder and $\mathrm{Cu}$, and there are no significant difference in the thickness and morphology. Both solders presented a reticular microstructure (eutectic zone), and these reticular microstructures encircled the $\beta$-Sn phase. Comparing with the metallograph (Fig. 2), these microstructures were relatively smaller, indicating that the faster cooling rate affected microstructure size. The proposed PV ribbons were soldered to $\mathrm{Ag}$ electrode on $\mathrm{Si}$ substrate at $250^{\circ} \mathrm{C}$ for $10 \mathrm{~s}$, and the interfacial microstructures (SAC/Cu, $\mathrm{SAC} / \mathrm{Ag}$ ) were acquired (Fig. 5). The interfacial microstructures from $\mathrm{A} 1$ to $\mathrm{A} 3$ were the upper solder $/ \mathrm{Cu}$ interface, the lower solder/Cu interface and the lower solder/Ag interface, respectively. The IMCs were clearly found in all interfaces that associated with thermal-induced diffusion behavior. ${ }^{18,19)}$ In the case of A1 and A2 interfaces, whether 
(a)

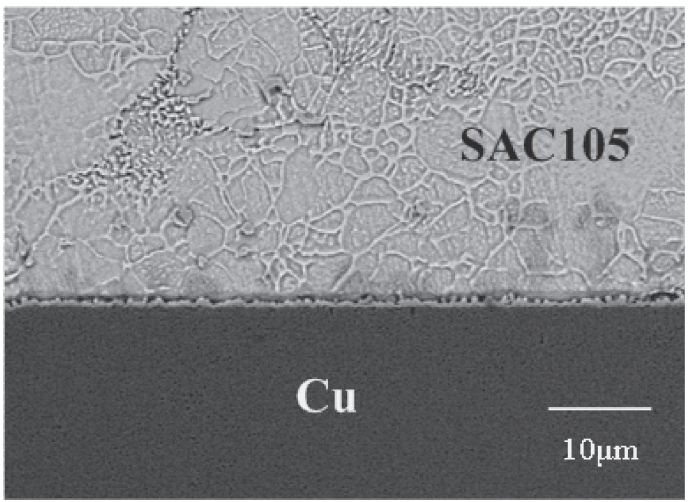

(b)

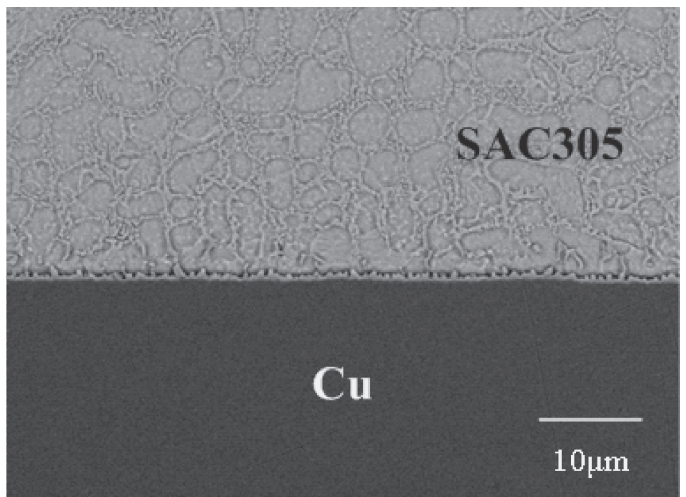

Fig. 4 The interfacial microstructure between solder and $\mathrm{Cu}$ : (a) SAC105 and (b) SAC305 solders.

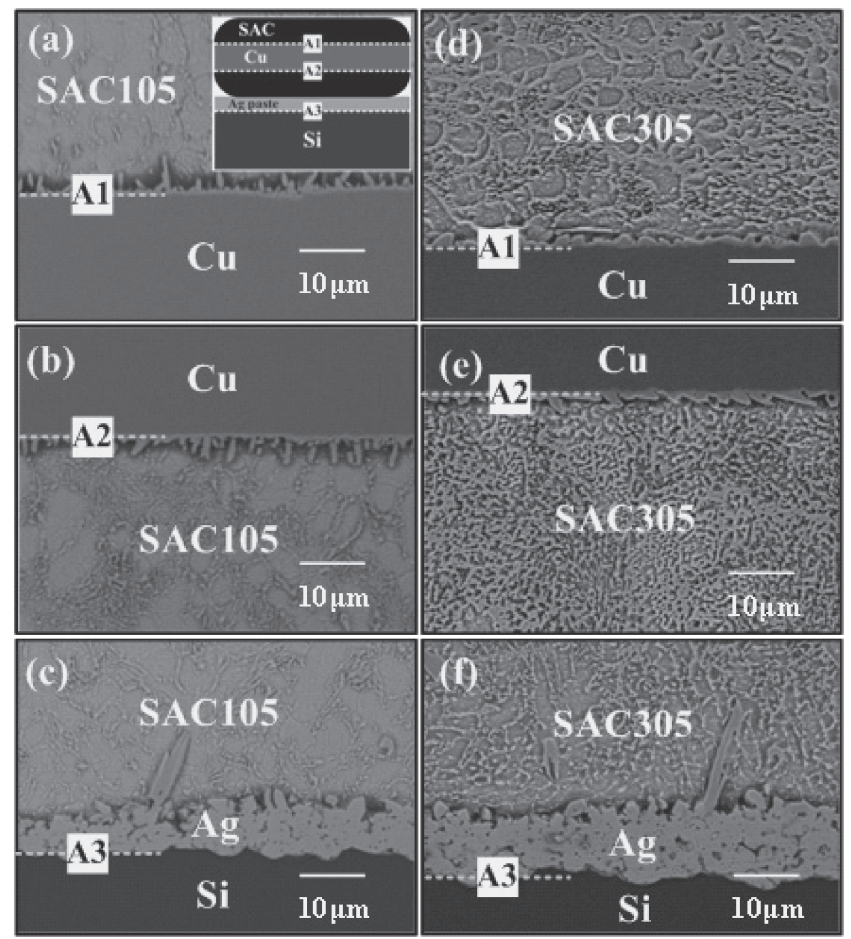

Fig. 5 The interfacial microstructures of PV ribbons after soldering for (a) SAC105 and (b) SAC305 solders.

the SAC105 solder/Cu interfaces or the SAC305 solder $/ \mathrm{Cu}$ interfaces, the IMCs layers were not distinctly difference in the thickness and morphology. In the case of the SAC105 solder/Cu interfaces (Figs. 5(a), 5(b)), the IMCs layer with a great amount of the pillar-like structures was formed. The

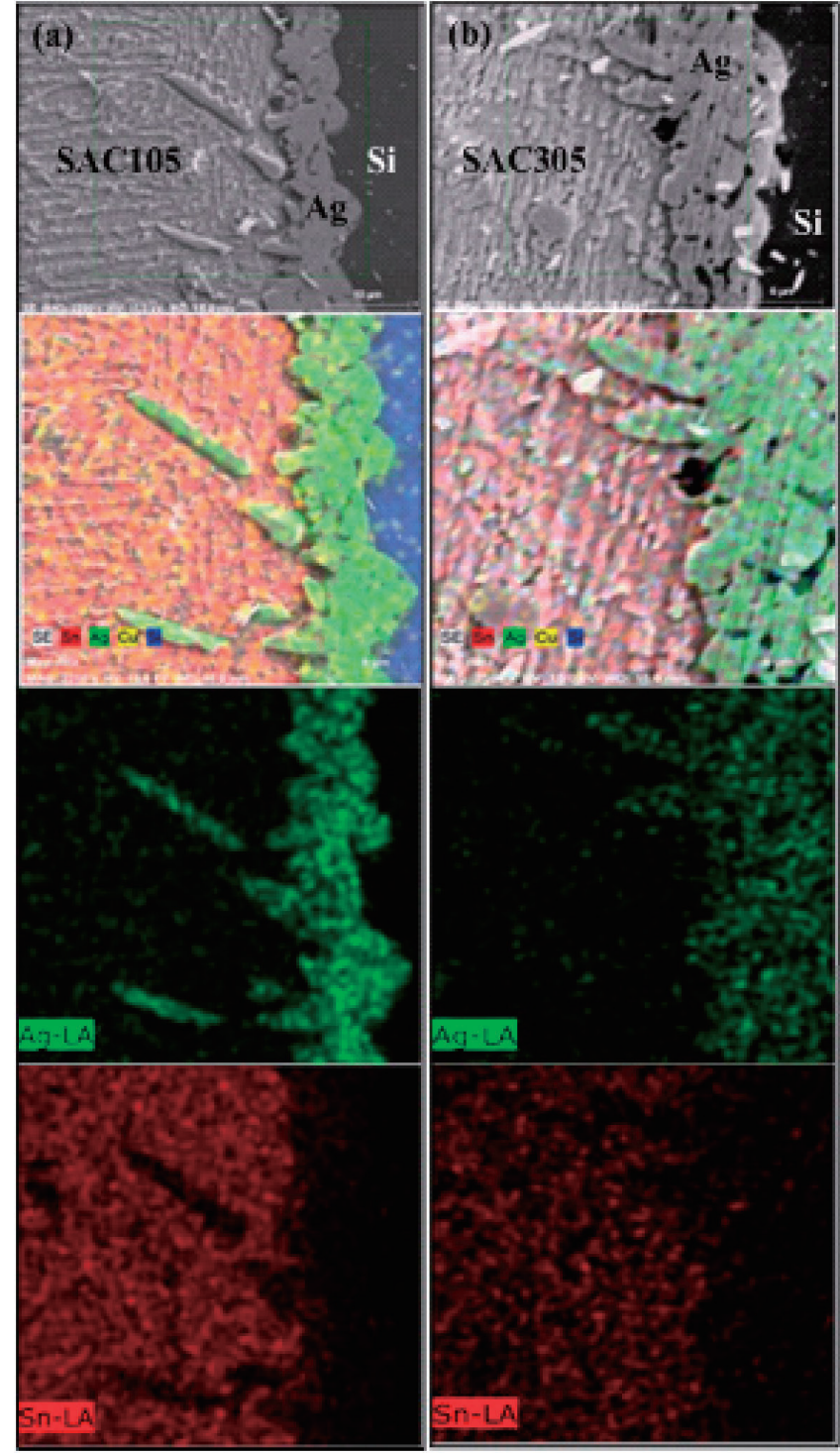

Fig. 6 EDS mapping at the interface bewteen the SAC solders and Ag electrode for (a) SAC105 and (b) SAC305 alloys.

IMCs morphology of the SAC305 solder/Cu interfaces presented a scallop-like shape (Figs. 5(d), 5(e)). Previous literatures indicated that these IMCs structures were corresponding to $\mathrm{Cu}_{6} \mathrm{Sn}_{5}$ phase. ${ }^{9)}$ In addition, some pillar-like IMC structures were grown at the $\mathrm{SAC} / \mathrm{Ag}$ interface (Figs. 5(c) and 5(f)). The morphology of Ag electrode presented an irregular shape and had the pores inside, indicating that the short reflowed time caused the reaction time was not enough. In order to determine the composition of pillar-like IMC structure, the interface characteristics (A3) were also detected using EDS mapping, as shown in Fig. 6. $\mathrm{Ag}$ was the main element in pillar-like IMCs, indicating that the composition of the pillar-like structure was dominated by $\mathrm{Ag}_{3}$ Sn phases. ${ }^{9)}$ This result was attributed to Sn in SAC alloy reacted with $\mathrm{Ag}$ to form the $\mathrm{Ag}_{3} \mathrm{Sn}$. Notably, the amount of the at the SAC105 solder/Ag interface was more than that in the SAC305 solder/Ag interface. The main reason for this was the higher Ag concentration gradient between the SAC105 solder and Ag electrode, causing more Ag to be fused into solder to form pillar-like $\mathrm{Ag}_{3} \mathrm{Sn}$ IMC. Meanwhile, 


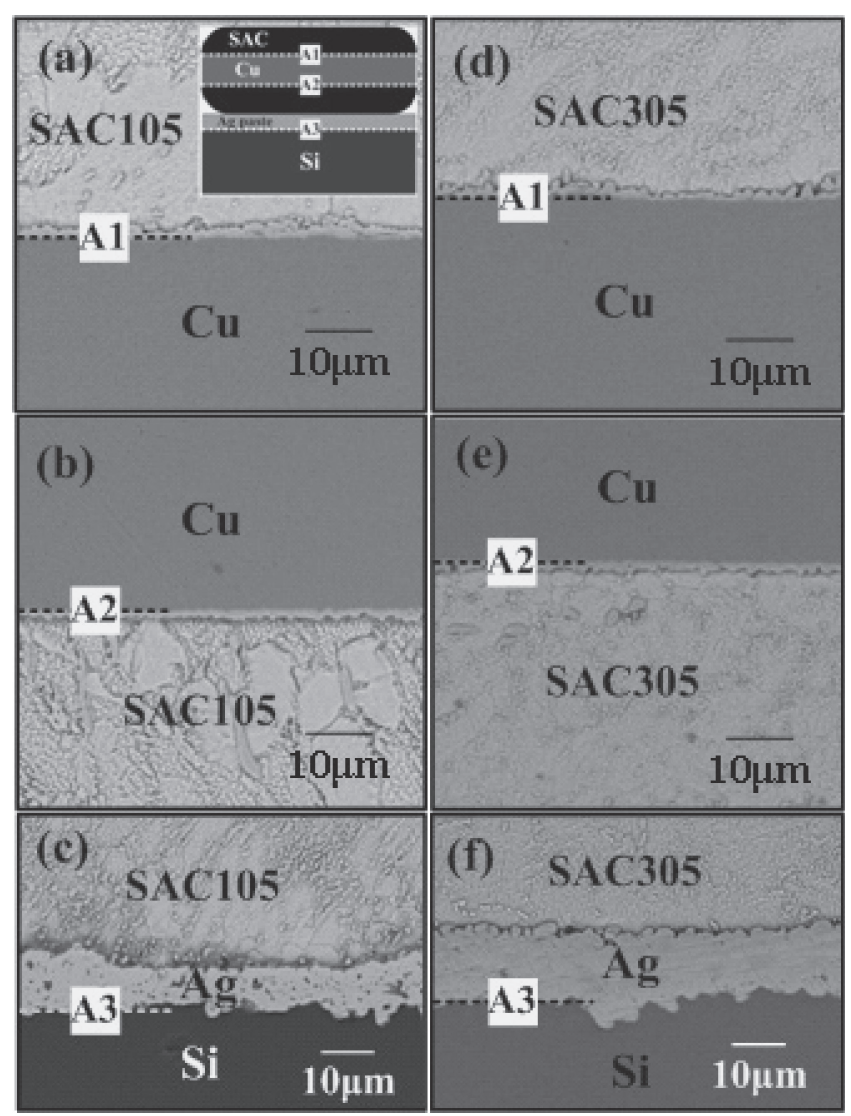

Fig. 7 The interfacial microstructures of PV ribbons after biasing for $40 \mathrm{~h}$ : (a) SAC105 and (b) SAC305 solders.

this IMC growth mechanism also caused $\mathrm{Ag}$ electrode decreased in thickness. In addition, some $\mathrm{Cu}_{6} \mathrm{Sn}_{5}$ phases existed in IMC structure due to the consumption of solder, and then were adsorbed to the interface.

To understand the influences of biased treatment on the interface characteristics, PV ribbon was biased for $40 \mathrm{~h}$ at room temperature. Figure 7 shows the interfacial images of $\mathrm{PV}$ ribbons after biasing for $40 \mathrm{~h}$. The whole interfacial layer of the $\mathrm{Cu}_{6} \mathrm{Sn}_{5}$ IMC (A1, A2) increased in thickness after biased for $40 \mathrm{~h}$, and the morphology was changed from the pillar-like (Figs. 5(a), 5(b)) to the layer-shaped (Figs. 7(a), 7(b)). In the case of the $\mathrm{Ag}_{3} \mathrm{Sn}$ IMC (A3), their morphology trended to become planar (Figs. 7(c), 7(f)) compared with the soldered PV ribbon (Figs. 5(c), 5(f)). These growing behaviors were controlled by the diffusion mechanism, and the growing dynamics were consistent with the parabolic law. ${ }^{9)}$

These interfacial IMCs will affect the efficiency and compatibility of PV ribbon on solar cell, therfore, the electrical resistances of the PV ribbons with different biasing time were measured (Table 1). Whether the SAC105 or SAC305 solders, the body resistances increased after biasing for $40 \mathrm{~h}$. Due to the $\mathrm{Cu}_{6} \mathrm{Sn}_{5}$ and $\mathrm{Ag}_{3} \mathrm{Sn}$ IMCs (high resistance phases) increased in thickness. ${ }^{15,20)}$ Comaring the SAC105 with SAC305, a body resistances of SAC105 PV ribbons were higher. In SAC105/Ag and SAC305/Ag interfaces, the thickness of $\mathrm{Ag}_{3} \mathrm{Sn}$ IMCs were not significant difference after biasing. But the SAC105 solder (low Ag concentration) resulted in the reduction of $\mathrm{Ag}$ electrode thickness. Briefly, a
Table 1 Total resistance of the PV ribbon with different alloy solders as a function of biasing time.

\begin{tabular}{ccc}
\hline Solder & Biasing time $(\mathrm{h})$ & Resistance $(\Omega)$ \\
\hline \multirow{2}{*}{ SAC105 } & 0 & 0.068 \\
\cline { 2 - 3 } & 40 & 0.070 \\
\hline \multirow{2}{*}{ SAC305 } & 0 & 0.052 \\
\cline { 2 - 3 } & 40 & 0.065 \\
\hline
\end{tabular}

residual Ag thickness of the SAC105 PV ribbon was thinner than that of the SAC305 PV ribbon. In other words, the low Ag content SAC105 solder was faster to enhance the internal resistance of PV ribbon, which was more quickly to effect the photocurrent conversion efficiency of the solar cell.

\section{Conclusions}

This study estimated the feasibility of $\mathrm{Sn}-x \mathrm{Ag}-0.5 \mathrm{Cu}$ $(x=1,3$ mass $\%)$ solders in PV ribbon application. The high amount of a eutectic area (high resistance phase) in SAC305 alloy presented a discontinuous distribution, and reduced the fusion current density. After soldering, the $\mathrm{Cu}_{6} \mathrm{Sn}_{5}$ and $\mathrm{Ag}_{3} \mathrm{Sn}$ IMCs were formed at the $\mathrm{SAC} / \mathrm{Cu}$ interfaces and $\mathrm{SAC} / \mathrm{Ag}$ interfaces, respectively. SAC105/Ag interface had more pillar-like $\mathrm{Ag}_{3} \mathrm{Sn}$ IMC structure, and caused $\mathrm{Ag}$ electrode reduced in thickness, that increased the series resistance of PV ribbon. Bias-induced thermal diffusion mechanism would cause a thickness of IMCs $\left(\mathrm{Cu}_{6} \mathrm{Sn}_{5}, \mathrm{Ag}_{3} \mathrm{Sn}\right)$ to increase, while the transformation of IMCs morphology attributed to the growth dynamics. In the case of the SAC105/Ag interface, the thickness of residual Ag electrode was thinner after the bias aging, which enhanced the series resistance of PV ribbon.

\section{Acknowledgements}

The authors are grateful to the Instrument Center of National Cheng Kung University, the Center for Micro/Nano Science and Technology (D101-2700) and NSC 101-2221-E006-114 for the financial support.

\section{REFERENCES}

1) W. C. Yang, H. C. Ay and Y. J. Ciou: Int. Symp. Transport Phenomena, (2011, 8-11 November, Delft, Netherlands) pp. 11-12.

2) D. R. Frear: IEEE Trans. Compon. Hybrids Manuf. Tech. 13 (1990) 718-726.

3) Y. T. Chiu, K. L. Lin and Y. S. Lai: J. Mater. Res. 23 (2008) 18771881.

4) M. T. Jahn and A. R. Saavedra: J. Mater. Sci. Lett. 11 (1992) 15961598.

5) J. Glazer: J. Electron. Mater. 23 (1994) 693-700.

6) Y. W. Yen, M. C. Lin, C. K. Lin and W. C. Chen: J. Electron. Mater. 41 (2012) 3284-3291.

7) P. D. Pereira, J. E. Spinelli and A. Garcia: Mater. Des. 45 (2013) 377383.

8) P. Liu, P. Yao and J. Liu: J. Alloy. Compd. 486 (2009) 474-479.

9) G. Zeng, S. B. Xue, L. Zhang, L. L. Gao, W. Dai and J. D. Luo: J. Mater. Sci. Mater. Electron. 21 (2010) 421-440.

10) Y. Kariya, T. Hosoi, S. Terashima, M. Tanaka and M. Otsuka: J. Electron. Mater. 33 (2004) 321-328. 
11) M. Amagai, Y. Toyoda and T. Tajima: Electronic Components and Technology Conference, (2003, 27-30 May, New Orleans, Louisiana, USA) pp. 317-322.

12) Y. Kariya, T. Hosoi, S. Terashima, M. Tanaka and M. Otsuka: J. Electron. Mater. 33 (2004) 321-328.

13) Y. Tian, Q. M. Zhang and Z. Q. Li: Solid State Commun. 151 (2011) 1496-1499.

14) K. W. Moon, W. J. Boettinger, U. R. Kattner, F. S. Biancaniello and C. A. Handwerker: J. Electron. Mater. 29 (2000) 1122-1136.

15) Y. Tian, Q. M. Zhang and Z. Q. Li: Solid State Commun. 151 (2011)
1496-1499.

16) L. H. Xu and J. H. L. Pang: J. Electron. Mater. 35 (2006) 2107-2115.

17) K. J. Chen, F. Y. Hung, T. S. Lui, S. J. Chang and Z. S. Hu: Mater. Trans. 52 (2011) 1560-1564.

18) W. Q. Peng, E. Monlevade and M. E. Marques: Microelectron. Reliab. 47 (2007) 2161-2168.

19) R. K. Chinnam, C. Fauteux, J. Neuenschwander and J. Janczak-Rusch Acta Mater. 59 (2011) 1474-1481.

20) J. F. Li, P. A. Agyakwa and C. M. Johnson: J. Alloy. Compd. 545 (2012) 70-79. 